\title{
Emerging principles for the allocation of academic work in universities
}

\author{
John Kenny ${ }^{1}$ (D) Andrew Edward Fluck ${ }^{1}$ (D) \\ Accepted: 23 July 2021 / Published online: 29 July 2021 \\ (C) The Author(s), under exclusive licence to Springer Nature B.V. 2021
}

\begin{abstract}
Internationally, much has changed in the governance of universities since the adoption of corporate management approaches. A strong focus on efficiency, productivity and accountability arising from these approaches has been well documented in the literature. Reductions in government funding have caused universities to become more competitive and entrepreneurial. However, little is known about the impacts of these changes on the working lives of individual academics. This paper is part of an ongoing study exploring the lived experiences of 2526 Australian academics who responded to a national questionnaire. This paper builds on earlier work by holistically drawing together the earlier findings which separately analysed the teaching, research and administration/service aspects of their work. In examining the effectiveness of universities through the ability of their academics to undertake their roles, we found the voices of academics that need to be heard in the development and implementation of key policies, such as academic workload and performance, to preserve the essentially self-managed nature of their work. By combining the learning from the project through the literature review, the statistical analysis and themes from the open-ended questions, we developed a set of principles to underpin these policies in universities. These principles can guide universities to shift towards a more collaborative working relationship with academics, based on trust, and actively encourage them to play be more active in institutional decision-making, especially in relation to policies that directly affect their work. These results have implications for improving the productivity of academics and the institutions in which they work.
\end{abstract}

Keywords Academic workload · Performance · Principles for allocating work $\cdot$ Effectiveness

John Kenny

John.Kenny@utas.edu.au

Andrew Edward Fluck

Andrew.Fluck@utas.edu.au

1 Faculty of Education, University of Tasmania, Locked Bag 1307, Launceston, TAS 7250, Australia 


\section{Introduction}

In many countries, neo-liberalism has impacted how universities function, through greater external accountability and an expectation to be more entrepreneurial and competitive (Bolden et al. 2012; Fredman \& Doughney, 2012; Furlong, 2013). In universities in Australia and the UK, this resulted in a shift from collegial self-governance to top-down corporate approaches and "increasingly marketised and competitive environment" (Guthrie et al., in review, p.5; Furlong, 2013).

In Australia, reduced government funding for universities is coupled with an expectation to become more efficient and productive (Marginson \& Considine, 2000; Norton et al., 2018). Yet, while numerous efficiencies have resulted from these changes (Hénard \& Mitterle, 2010), deeper questions have arisen about the core-purpose of universities (Barry, 2019; Harman \& Treadgold, 2007) where "productivity" is often conflated with "efficiency", despite these being fundamentally different concepts (Marginson \& Considine, 2000). As productivity (effectiveness) relates to the core-purpose of an organisation, it involves value judgements about what should be done, while efficiency relates to doing it with minimal effort and cost. Thus, considerations of effectiveness should precede those of efficiency (Kenny, 2009).

Accompanying these changes, researchers have noted the loss of power of academics within their institutions and intensification of their work (Bolden et al. 2012; Boyd, 2014; Coates \& Goedegeburre, 2012; Henkel 2005; Mitchell, 2015; Ryan et al. 2013). Much of this literature has focussed on the effects of change on universities, as institutions. However, as Gill (2014) noted, their effects on the working lives and careers of individual academics have gone "almost entirely undocumented" (p.13).

Our goal has been to address this gap, by exploring the effects of these sector-wide policy changes from the perspective of individual academics across Australia. To our knowledge, there is no equivalent analysis at this level of detail in the published literature. To begin, we draw on the literature to understand what academic work entails.

\section{Literature defining academic work}

An academic's workload comprises a complex mix of teaching, research and service/ administration duties, but the proportions of these duties can vary considerably for individuals according to their experience level and discipline. Studies have suggested time-based approaches to allocating academic work are most credible, provided: academics have been involved in their development, they contain a holistic and realistic array of time allocations for the tasks, the work allocation process is transparent, and the budget process ensures the adequate allocation of resources (Burgess et al., 2003; Kenny et al., 2012; Kenny \& Fluck 2014; Vardi, 2009). However, this earlier work lacks detailed guidance on appropriate time allocations for various tasks.

Our research set out specifically to address this situation. A questionnaire was sent to academics at every university in Australia. It gathered detailed information from 2526 academics about, their work, including quantitative time estimates for many tasks associated with their teaching, research and service/administrative roles. This was supplemented by qualitative data, as open text comments, on their lived experiences with academic workload allocation and associated performance policies in their institutions.

The first phase of this research involved extensive analysis of these data resulting in tables of detailed time estimates for a wide-range of teaching, research and service/administrative 
tasks, respectively (Kenny \& Fluck, 2017, 2018, 2019). As, in the published literature there is no equivalent analysis, at this level of detail describing the work of Australian academics, this paper necessarily builds on this work. We further contend the findings will be relevant for academics more globally.

This paper concludes phase one of the research and has two aims: first, to provide a holistic view of the issues; and second, to use the overall findings and literature, to identify underlying principles for the allocation of academic work and associated processes. These principles should serve the interests of academics and their universities and be applicable to a wide-range of individual circumstances. They should be able to inform policies and processes related to managing academic work and performance, in a manner that is credible and reflective of the work academics undertake.

\section{Policy impacts on academic work and their institutions}

In many countries, productivity demands require universities to compete for funding and meet external performance metrics, such as Excellence in Research for Australia (ERA) (Kwok, 2013). This drive to maximising research output and reputation creates pressure to publish in the "higher-ranked" journals, limits what "counts as research", and devalues non-traditional outputs, such as creative materials and live performances (Fredman \& Doughney, 2012; Kenny, 2017; Kwok, 2013).

With less control over their work and how their performance is judged (Cannizzo \& Osbaldiston, 2016; Houston et al., 2006). This is compounded by increased use of shortterm contract employment (Ryan et al. 2013) in teaching, and research, resulting in a "devaluing of the critical teaching-learning-research-practice nexus in education institutions" (Yielder \& Codling, 2004, p.321), and the commodification of knowledge (Fleissner, 2006; Kauppinen, 2014).

A fundamental "clash of values" is evident between bureaucratic and academic approaches, in the reduced influence of academics over decision-making within their institutions (Mitchell, 2015; Roberts, 2013; Yielder \& Codling, 2004). The subsequent loss of academic voice on important questions undermines the autonomy and intrinsic motivation typically associated with academic work (Boyd, 2014; Fredman \& Doughney, 2012; Houston, Mayer \& Paeweai, 2006). In this climate, the notion of academic freedom is challenged and individual competition can distort the research process and lead to "gaming" strategies (Söderlind \& Geschwind, 2019, p.76).

Robert's (2013) prediction of an "emerging academic dystopia" is revealing itself in Australian universities. The rate of casualisation in the Australian higher education sector was reported as the third highest of all sectors (Ryan et al., 2013). Langford (2010) reported relatively high levels of stress for university staff in comparison to other industries. More recently, Vesty et al. (2018) identified "burnout" in academics from Australia and New Zealand due to workload pressures and loss of control over their work. The Queensland Office of Industrial Relations (2018) reported an increase of serious compensation claims in the tertiary education sector of 18.9\% per annum between 2009 and 2014. Nationally, these rises have occurred against a backdrop of a $17 \%$ decrease for all industries (Safe Work Australia, 2021, p.32).

Indications are that the intensification of academic work, in the name of efficiency, has its limits. High levels of stress are likely to undermine the delivery of high-quality teaching and research, and therefore diminish the effectiveness of universities. This suggests that the working relationship between academics and their institutions needs some serious re-thinking. 


\section{A path forward: institutional effectiveness and the work of academics}

If university governance should serve teaching and research as their core business (Harman \& Treadgold, 2007), then universities need to re-think "the structures, relationships and processes through which...policies for tertiary education are developed, implemented and reviewed" (Hénard \& Mitterle, 2010, p.26). However, Roberts (2013) warns against a "return to a romanticised version of the university of the past", arguing instead for a governance model capable of "acknowledging the importance of the tension between ideals and realities" (p.41). But if, "traditional collegial decision-making" remains "so important to the university idea" (Bebbington's, 2021, p.159), universities need to go beyond mere "acknowledgement" of these tensions and explore ways to work more effectively with academics.

Others identify trust as the cornerstone of a better relationship between academics and their institutions (Barry, 2019; Harman \& Treadgold, 2007). Trust, however, needs to be fostered by processes which genuinely allow a voice for "the academic profession who perform the work of the academic 'core' and who possess specific professional norms and behaviour" (Harman $\&$ Treadgold, 2007, p.25). Barry (2019) went further, imploring academics "to re-engage, and be encouraged to re-engage, in governance where their expertise best fits". However, in corporate universities, this adjustment to the existing power dynamic clearly presents a challenge to both academics and their managers.

From the above discussion, sectoral policies on funding and productivity translate into institutional policies that directly affect how academics work. Thus, care must be taken to ensure these policies protect the essence of academic work. More specifically, Barrett and Barrett (2008) argued, "given the centrality of staff to the success of universities", the way institutions determine and judge academic work, should be seen as "major strategic process which if not done well can disable the organisation" (p.6).

These ideas challenge the typically dismissive view of academic workload allocation as a low-level operational issue. Barrett and Barrett (2008) maintain it is central to a university being effective, so its implementation needs to be coherent with other key policies and resourced accordingly. It is also central to building trust and needs to be developed in consultation with academic staff to ensure its credibility and acceptance. Indeed, if this is "effectively and authentically handled universities can create strong socio-temporal contracts with their staff that embody the vision of the university" (p.6).

Others have demonstrated a lack of coherence in related institutional policies through widespread adoption of individual performance management, without its adaptation to suit the intrinsically motivated, highly cognitive and autonomous nature of academic work (Franco-Santos et al., 2014; Kenny, 2008, Morris, 2011; Pink, 2010). Indeed, for example, Kenny (2017) and Kenny and Fluck (2018) identified that 94\% of academics see a clear link between workload allocation and their research performance.

\section{Important contextual background to this paper}

All Australian universities negotiate an enterprise agreement to determine working conditions for their employees. Each agreement includes an academic workload clause, which typically states an annual maximum number of hours of work (derived assuming a working week of about 38 hours) that can be allocated to an individual academic. However, how this is done, and the times allocated for the tasks undertaken in an individual's workload, remains largely a 
matter for local workgroups to decide (NTEU, 2020). This results in some form of local or institutional workload allocation process. Earlier workload studies claimed that the processes by which the academic workload and performance processes are developed and implemented are crucial (Burgess et al., 2003; Vardi, 2009). However, as Papadopoulos (2017) noted, too often these models have been manipulated, particularly with the power imbalances in universities alluded to earlier. Failure to properly consult with academics on the impacts of change leads to "major changes to educational practices" being "introduced through alterations to (workload) models" rather than by consultation and consideration of the impact upon academic workers" (Papadopoulos, 2017, p.522). Thus, while the existence of a workload allocation model is necessary for fairness, it is not sufficient.

Given that there is limited published data in this area, we will briefly summarise the major findings from our three published papers, as important background and a link to the purposes of this paper.

The first paper, Kenny and Fluck (2017), after extensive statistical analysis, presented tables giving median hours for a wide-range of specific teaching-related tasks, including, for example, unit coordination, preparation of lectures, tutorials, studio classes, student assessment and consultation. It also explored how factors such as experience and discipline affected these figures. It found differences due to the mode of teaching (online or on-campus delivery), which is particularly pertinent for monitoring the impact on workloads, due to the shift to online learning across the sector during the COVID pandemic, also, in dealing with the workload impacts on remaining staff due to the subsequent loss of 17,300 jobs in higher education (Universities Australia, 2021).

A similar analysis in Kenny and Fluck (2018) provided median times for a wide-range of research-related tasks such as preparing a grant application, preparing a refereed journal article for submission and supervising research students. As a workload analysis, it drew a clear distinction between research workload (or input) and research productivity (or output). More specifically, research workload refers to the time needed to undertake a range of research activities, whereas productivity concerns the outcomes of this work, such as published articles, thesis completions or successful grants.

This inputs-based approach to research workload is very different from what typically happens in Australian universities, where the research component of academic work is usually determined retrospectively, based on research outputs. Which, Papadopoulos (2017) argues:

“...take past performance (construed narrowly as outputs) as indicative of future potential, and reallocate academic time according to judgements which precede consideration of aspirations or underlying constraints..." (p.523)

Kenny and Fluck (2019) identified a wide-range of academic administrative and service activities. Respondents provided indicative times for many examples of both formal and informal tasks. Service work was also categorised as internal or external to the institution, strategic or operational in nature. It confirmed the centrality of this work for the proper functioning of universities and the sector as a whole, but noted that often, these tasks were not adequately accounted for in individual workloads. Many academics reported the administrative demands on their time had increased significantly.

Together, these findings provided a detailed and holistic set of quantifiable time-based metrics for a wide-range of activities, encompassing teaching, research and administration/ service. Some combination of these forms is the basis of any individual academic's workload (Vardi, 2009). Holistic and detailed data concerning academic work has not been published 
before for Australian universities. Contrary to criticism of previous approaches to workload (Papadopoulos, 2017), these data have proceeded "from the real" (p.514), because the allocations were derived from data supplied by the participants in the study.

\section{Methodology}

Grounded Theory (Glaser \& Strauss 1967; Strauss \& Corbin, 1990), a methodology by which theory emerges from the data, through inductive analysis underpins this research project. This supports the emergence of underlying principles from the data, as a step towards a theoretical foundation for these claims. To be comprehensive, the questionnaire was open to academics, regardless of their discipline, experience, academic level or career focus, and consisted of 80 questions.

This paper builds on our previous work by providing an analysis of the respondents' experiences with workload and performance policies, as expressed through their written responses to the final four questions:

1. In your experience, what are the main strengths of the current approach to the allocation of academic work at your institution?

2. In your experience, what are the main challenges to the fair allocation of academic work at your institution?

3. In your experience, what are the main reasons for the challenges you mentioned in the previous question?

4. Please make any final remarks on academic workload and/or performance management based on your experience.

\section{Details of the sample}

A total of 2526 academics responded to the questionnaire. This paper is concerned with the sub-sample of 1047 (41.5\%) who responded to at least one of the four questions above. We cannot claim this sub-sample to be fully representative, as there were differences with the government data available for the sector at the time (Australian Government, 2017), as outlined below.

The gender distribution, with 437 (41.7\%) males, 604 (57.7\%) females and six reporting as "other", was consistent with the national proportions ( $43.5 \%$ male and $56.5 \%$ female). Differences were noted, however, in the spread of academic levels and workload categories between the national data and the sub-sample.

Table 1 shows the professoriate (Levels D \& E) accounted for $20.1 \%$ of respondents, which is lower than the $28.8 \%$ reported nationally for full-time equivalent academics at the time. Most respondents in the sub-sample (74.1\%) were mid-career academics (Levels B and C), which is much higher than the national proportion of $47.4 \%$. Only $5.5 \%$ of this sample were sessional staff which is lower than the $17.5 \%$ reported nationally.

Comparing the spread of workload categories with the national data was more difficult. The national data reported on only four categories of academic "function" (Teaching only, Research Only, Teaching and Research and Other) indicating only 33.5\% of academics have a research role, with "Other" at 53.2\% and "Teaching Only" at $12.6 \%$. However, our sub- 


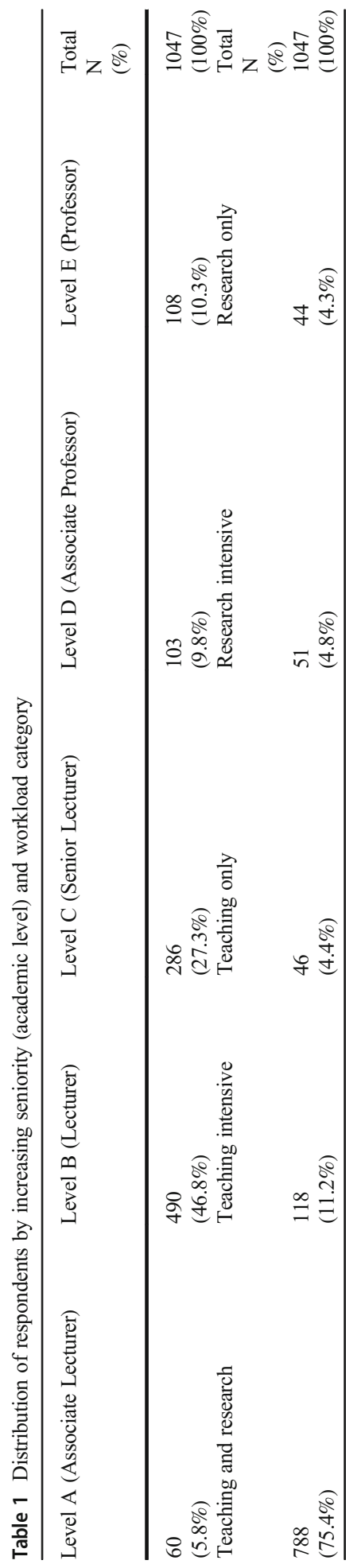


sample has five categories and most academics had some level of research or scholarship expectation within their role.

Table 1 shows the largest group of academics were "teaching and research" (75.4\%), who typically have approximately $40 \%$ of their time allocated to research and teaching. The other categories, either teaching or research was emphasised (e.g., "teaching intensive" staff typically have a $60 \%$ teaching load). In general, all respondents had a nominal $20 \%$ of their work allocated for service/engagement and administration duties.

While we acknowledge the limitations of self-reported data, the fact that the respondents were anonymous, voluntary and there was no power relationship involved, makes it likely they would frankly describe their individual experiences of the workload and performance management practices in their institutions.

\section{Individual experiences of academic workload and performance at their institutions}

Coding was used to generate a list of themes which were tallied. The resultant frequencies for the top four or five themes related to each question have been tabulated. In the discussion following, quotes have been used to illustrate typical responses, with each responder given a unique identifier, beginning with an $\mathrm{F}$ or $\mathrm{M}$ to indicate their gender, and ending with letters $\mathrm{A}-\mathrm{E}$, indicating the academic level in ascending order, where $\mathrm{A}=$ Associate Lecturer, $\mathrm{B}=$ Lecturer, $\mathrm{C}=$ Senior Lecturer, $\mathrm{D}=$ Associate Professor and $\mathrm{E}=$ Professor.

Of the 1047 who responded to at least one of the four questions, 475 responded to all four questions. A Chi-square analysis for each question showed homogeneity of respondents across all four questions, with no significant difference, at the $\mathrm{p}=0.05$ level, by discipline $\left(X^{2}(15)=3.001, p=.999\right)$, academic level $\left(X^{2}(12)=1.55, p=\right.$ $.999)$, gender $\left(X^{2}(6)=1.116, p=.981\right)$, years of experience as an academic $\left(X^{2}(12)=\right.$ 2.623, $p=.998)$ or work category $\left(X^{2}(12)=1.136, p=0.999\right)$. This allows for direct comparison across the question groups.

\section{Findings}

The respondents included academics from all but one of the 41 universities in Australia. The number of responses from any given university ranged between 72 and one. Twenty-three universities provided 20 or more respondents while thirty-six provided 10 or more. Of the respondents, $92.5 \%$ claimed they could not meet the requirements of their academic roles within the standard 38-hour working week. The average number of weekly working hours reported was consistent with other research at 50.8 (Tight, 2010, NTEU 2020).

The themes below emerged from the responses to each question. Table 2 gives a summary of the 885 responses to the first question. It shows that overall, $398(44.8 \%)$ identified specific strengths associated with the workload model at their institution. Of these, 178 specifically mentioned its transparency either directly, by referring to its visibility, or the clarity of the documentation. Two aspects of transparency were described: some mentioned transparency of the process, where they were confident that the same formula was used to determine the workloads of all individuals in their work area; others commented on transparency of outcome, where the estimated workload commitments of their colleagues were publicised. 
Table 2 Summary of emergent strengths in the process to allocate academic work at an institution.

\begin{tabular}{lll}
\hline Open-ended question & Identified theme & Frequency count (\%) \\
\hline $\begin{array}{l}\text { 1. In your experience, what are the } \\
\text { main strengths of the current approach } \\
\text { to the allocation of academic work }\end{array}$ & Specific strengths identified (n) & 398 \\
at your institution? $(\mathrm{N}=885)$ & Transparency (76), visibility (12), & $(44.8 \%)$ \\
& documentation (68), equity (22) & $(20.1 \%)$ \\
& Connection to performance: negotiating & 72 \\
& reasonable expectations (41) & $(8.1 \%)$ \\
& Collaborative and consultative & 44 \\
& Flexibility of model & $(5.0 \%)$ \\
& Partial strengths- attempts to develop & 23 \\
and/or implement a model & $(2.6 \%)$ \\
& local vs. institutional, manager discretion & $(16.4 \%)$ \\
& No strengths & 283 \\
& Unsure & $(31.8 \%)$ \\
& & 62 \\
\end{tabular}

Transparency was clearly the major factor in building trust in the process for these staff because it increased their confidence that the workload policy was being applied consistently and fairly:

My boss is transparent, everyone knows each other's loads and role. Very fair. [F4399965574B]

These comments were typically associated with a local workgroup model, where collegial trust was indicated in the responses, but respondents were less confident in their institutional workload process, where one existed. Consistent with Kenny (2018), 72 (8.1\%) of these academics felt the workload model enabled genuine discussion with their managers to negotiate reasonable workload outcomes and performance expectations:

Enables me to identify areas of overload and negotiate changes in performance management discussions with my supervisor.... Fairly well thought out and transparent. [M4442037887C]

This was particularly important for planning the more self-managed aspects of their workload, such as their research:

It is transparent, provides a good teaching/research balance, and leaves enough scope for my independent planning of my teaching and research agenda. [M4385737324B]

However, as Table 2 also shows, a further 146 (16.4\%) respondents also mentioned serious shortcomings. For example, while genuine attempts to capture their work were appreciated, the results were generally seen as inadequate, or seriously under-estimating the time required for many tasks:

...there is an attempt to put numbers on some of the tasks we do......but it is uninformed and unrealistic. [F391260690C]

Often, the respondents noted their model estimated their teaching quite well, but was of little use for other important aspects of their work, such as their service and research roles: 
Teaching is handled well. Research time allocation is abysmal. [M4398728328D]

This suggests that when developing workload models a holistic perspective on academic work is needed. The respondents saw consultation in the development of the model as important to getting the balance right:

...that it is specifically mentioned in the industrial agreement, so it can be enforced. That it was developed by a joint committee of staff and management. That it applies across the university. [M4369824359C]

However, consultation does not always translate into outcomes:

The process was highly consultative and collaborative; however, we are yet to see whether the outcome represents the input...Budget pressures mean many managers try to avoid implementing it fully. The process is not always as transparent as it should be. [M4332247869B]

These comments suggest that individuals find the allocation process credible if it clearly acknowledged all aspects of their work (i.e., was holistic) and was genuinely transparent, equitable and consultative.

Others commented on the need for more flexibility to suit individual circumstances as an equity issue. For example, the contracted academic below, felt the workload allocation process was inequitable because it ignored many implicit demands on her time as she tried to establish her career:

... as a staff member on a fixed term contract and establishing myself in a new field without a research team and building a research network from scratch there are enormous time requirements in place that must be met to secure ongoing employment. This creates... pressure, even if it is not explicit. [F4332345222A]

From above, while many of the 885 respondents pointed to specific strengths associated with the workload allocation process at their institution, the majority $(55.2 \%)$ of respondents also identified serious shortcomings or were unsure how it worked. Notably, of these, $283(31.8 \%)$ specifically commented that there were basically "no strengths".

The workload has NO relationship to hours actually worked. So we just are all equally under the same pressure. [F4335273806B]

This indicated widespread dissatisfaction with aspects of the workload allocation process overall, a point which was picked up more specifically by Question 2.

Question 2 drew the largest number of 1004 responses (96\%) and the themes are summarised in Table 3.

Of these, $275(27.4 \%)$ commented on the inadequacy of their model to capture their work, either because it under-estimated, or omitted time associated with certain activities altogether:

There is a lack of recognition of how much time it takes for effective teaching, coordination of units, mentoring sessional staff and administering to students' needs. [F4332326891B]

Many staff felt their managers did not fully understand the complexity of their work or set unrealistic expectations, especially in relation to research: 
Table 3 Summary of emergent challenges posed to the fair allocation of academic work

\begin{tabular}{lcl}
\hline Open-ended question & Identified theme & $\begin{array}{c}\text { Frequency } \\
\text { count (\%) }\end{array}$ \\
\hline $\begin{array}{c}\text { 2. In your experience, what are the main } \\
\text { challenges to the fair allocation of academic } \\
\text { work at your institution? }\end{array}$ & $\begin{array}{c}\text { Underestimation or omission of some key tasks } \\
\text { (e.g. marking, preparation, changing }\end{array}$ & 275 \\
$(\mathrm{~N}=1004)$ & numbers, online, research) & $(27.4 \%)$ \\
& Lack of transparency (e.g., process and outcome) & 154 \\
& favouritism and nepotism, inequities & $(15.3 \%)$ \\
& Inequities- Need to deal with individual and & 149 \\
& disciplinary differences (e.g., flexibility) & $(14.9 \%)$ \\
& Actions of senior management understaffing & 122 \\
& related to KPIs, bonuses, bullying, & $(12.1 \%)$ \\
& understaffing & \\
\hline
\end{tabular}

The amount of time awarded to activities is clearly insufficient; there are unrealistic expectations about research output, particularly since our institution provides minimal support. [M4335613377C]

More involvement of academic staff in its design and implementation would seem to be a way of ensuring the workload model more realistically captures the complexities of academic work. Indeed, several respondents suggested this approach:

More consultation is required with the staff who actually complete the tasks to gain a realistic idea of the actual time needed for specific tasks.

[M4444439140C]

Consistent with Papadopoulos (2017), these data indicate the existence of a workload model was insufficient to guarantee fairness. Attention needs also to be paid to how it was been designed and implemented.

Here, the lack of a workload planner that is constructed in a realistic way that accounts for all of these activities is a real problem, especially given the failure of management to see and understand the investment in time building research capability takes. [F4332345222A]

On the process to determine their workloads, 154 (15.3\%) reported a lack of transparency, with comments often related to the level of discretion their managers had when interpreting the model. This is also consistent with observations in the literature (Papadopoulos, 2017) and cast doubt on the credibility of the process:

The workload model is not available to staff - we receive a spreadsheet with made up numbers to fit 1725 hours per year, so it looks good on paper, but the reality is it does not fully reflect work required. [F4403502109B]

A further 149 (14.9\%) claimed their workload model lacks the flexibility to cater for individual circumstances or disciplinary differences:

Discipline groups should have greater autonomy over what it takes to do academic work within their disciplines. A one-size-fits-all [approach], is always going to be problematic. Some disciplines will come out on top, whereas others will suffer. [F4387756057B] 
Many believed their managers were under financial pressure from senior management, and the lack of transparency enabled workloads to be manipulated so that fewer staff were needed:

Obscure (non-transparent) workload model not developed in consultation with staff, with values that are changed to suit the budget. Ever decreasing budgets... Insufficient staff to do the work. [M367041176C]

Twenty specifically linked these pressures to poor management practices such as nepotism, favouritism, bullying or unrealistic expectations:

The process is not transparent, which means that nepotism and favouritism play a strong role in workload allocation. [F4441780015B]

The lack of trust evident in many of these responses supports calls for an institutional approach linking workload allocation to staffing decisions and budget considerations to ensure adequate resourcing (Barrett \& Barrett, 2008). Key principles emerging suggest consultation is needed to achieve a transparent, holistic and flexible approach to allocating academic work so that it realistically captures the work done.

The third question explored the respondents' opinions of the challenges to workload allocation (Table 4). It drew 882 responses, with the most frequent theme being "poor management" by $166(18.8 \%)$, linked to under-funding/budget concerns (136 or $15.4 \%)$.

Further, many academics specifically expressed a lack of trust or confidence in the senior management of their university, who they felt were "out of touch".

Top-down approach, lack of consultation with staff. Instructed on tasks to be included without consideration of the impact on the quality of teaching; the individual or the ability to manage given tasks at a given time. [F4390495615B]

When coupled with the diminished power of academic staff within their organisations, tensions arise because they feel exploited, leading to a lack of trust in the process:

The university system is increasingly based on systemic exploitation of workers. Management knows that academics will do research (and other work) in their own time and exploit that. [M4334809455B]

Table 4 Summary of emergent reasons for the challenges in allocating academic work

\begin{tabular}{lll}
\hline Open-ended question & Identified theme & Frequency count (\%) \\
\hline $\begin{array}{l}\text { 3. In your experience, what are the } \\
\text { main reasons for the challenges you } \\
\text { mentioned in the previous question? }\end{array}$ & $\begin{array}{c}\text { Poor management (top down) (compliance) } \\
\text { (change) (institution v. local) (out of touch) }\end{array}$ & $\begin{array}{l}\text { Under-funding leads to pressure on staff } \\
(\mathrm{N}=882)\end{array}$ \\
& Focuses on balancing budget & 136 \\
& & $(15.4 \%)$ \\
& Focus on balance between research and teaching & 74 \\
& & $(8.9 \%)$ \\
& Nepotism, bullying (e.g., sexism) & 70 \\
& & $(7.9 \%)$ \\
\hline
\end{tabular}


The experience of many respondents is of universities as financially stressed organisations, where there is little incentive for managers to ensure realistic estimates of the time needed for academic tasks:

It is getting well out of hand the teaching load and research expectations. It is not possible to juggle in 38 hours per week. We are losing administrative supports and the worst part is that the university administration is not listening to our feedback about the changes. It's a quite frustrating and sad time to be an academic at this institution. I feel we are losing our professionalism and next will be our reputation as quality teachers which has historically been a strength for us. [F4441938933B]

They felt the workload process was manipulated to control the budget rather than genuinely capturing the work done or ensuring adequate staffing:

Management appears to take the view that research is not a significant priority and is something that staff have to do in their own time outside of teaching and admin duties. It is not genuinely recognised as being part of the academic role. One of the reasons is saving money on casuals - getting full-time staff, especially ECRs ${ }^{1}$, to do as much teaching as possible. [F4395035907B]

These data confirm "conflicts between bureaucratic, corporate and scholarly logics" (Papadopoulos, 2017, p.515). Many academics felt that their dedication to their work is taken advantage of and linked this to a lack of consultation in framing their workload allocation and performance processes, which are not reflective of the realities of their work. Further, when concerns have been raised, they were either not addressed, or were suppressed:

The allocations against the lived experience of teaching and research are completely inadequate. There is also little transparency between staff or forums to raise any concerns about inequitable workloads...Zero consultation or dialogue. Bullying from senior management when concerns have been raised. [F4413222093B]

For credibility, both university managers and academics need to be clear that the primary purpose of workload allocation is to provide a realistic and holistic picture of the actual demands on staff. Decisions about what changes need to be made to programmes, on budgetary grounds, should be informed by realistic estimates, not fictitious or manipulated data. This clearly places workload allocation as an important institutional issue (Barrett \& Barrett, 2008).

An effective workload policy would provide academic staff and performance managers with easy access to, and training in, the use of transparent and realistic mechanisms to accurately estimate individual workloads, so programs could be staffed adequately.

The final question drew 564 responses, with many re-iterating some of the earlier comments (Table 5). Ninety-seven (16.3\%) emphasised workload models need to be holistic and account for research activities as comprehensively as for teaching.

Research needs to be quantified in hours too, not just by outputs. [M4332245943C]

More generally, the nexus between performance, career development opportunities and workload allocation was emphasised by $92(15.4 \%)$.

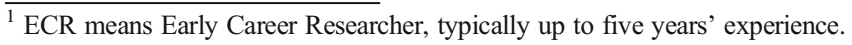


Table 5 Summary of emergent themes on the processes to allocate academic work and/or judge performance

\begin{tabular}{|c|c|c|}
\hline Open-ended question & Identified theme & $\begin{array}{l}\text { Frequency } \\
\text { count }(\%)\end{array}$ \\
\hline \multirow{4}{*}{$\begin{array}{l}\text { 4. Please make any final remarks on academic } \\
\text { workload and/or performance management based } \\
\text { on your experience } \\
(\mathrm{N}=564)\end{array}$} & $\begin{array}{l}\text { Models need to include research activities } \\
\text { (e.g., especially for junior staff) }\end{array}$ & $\begin{array}{l}97 \\
(16.3 \%)\end{array}$ \\
\hline & $\begin{array}{l}\text { Poor performance management process } \\
\text { (e.g., need to acknowledge all } \\
\text { contributions) }\end{array}$ & $\begin{array}{l}92 \\
(15.4 \%)\end{array}$ \\
\hline & $\begin{array}{l}\text { Not linked to developing staff capabilities } \\
\text { (e.g., promotion mentoring) }\end{array}$ & $\begin{array}{l}18 \\
(3 \%)\end{array}$ \\
\hline & Lack of trust or respect of academic staff & $\begin{array}{l}18 \\
(3 \%)\end{array}$ \\
\hline
\end{tabular}

I have spent four years trying to get a research track record, working up to 80 hours a week... The last two years my admin load has doubled. As a course coordinator it is impossible to publish at all. I have now refused to continue in the role of course coordinator. [M4439883317C]

Related to this, but less prominent, were 18 comments linking workload to promotion pathways and mentoring. Flaws in the workload meant that much of their work was "hidden".

What is written on paper in terms of hours re admin or research does not correspond to the actual time spent. It all looks fine on paper but has enormous hidden workloads. [M4464892648B]

This led to inequities and stress, particularly for less experienced researchers, often coping with heavier teaching loads:

It is a winner takes all model - a few successful researchers get to teach nothing and further their research while the rest of us are becoming more and more teaching intensive with less and less opportunity to do research - teaching is being used as a trap - a form of punishment. [M4386370205B]

These findings underscore the need for a holistic approach to estimating workload and judging performance, because a failure to do so can have a direct bearing on an individual's welfare and ability to perform key tasks, especially research.

I cannot see how setting the minimum performance requirements so high that you demoralize your staff and create permanent anxiety and depression can help performance. I must work through all holidays that I am obliged to take. [F4440006955B]

The associated frustrations and feelings of exploitation were widely held, implying a need for a stronger academic voice in decision-making about these matters that directly affect their work:

The students must be taught, and the show must go on. They play on our loyalty to provide a service to students, and we fall for it every time as we don't want students missing out. I don't know an academic who can half do their job as we never want to let the students down. [M4347370138A]

When specifically asked to explain changes to their workload in recent time, the respondents mentioned increased expectations across the board in teaching and research, with $45 \%$ also 
mentioning increased administrative demands, often linked to the introduction of online systems

High intensification as we move from a paperless university and computer systems become more savvy there is an incredible amount of work that is now done by the academic on the desktop that was not the case 5 years ago

\section{Discussion and conclusions}

Our research and the literature suggest that, while the corporate top-down approach prevalent in our universities may have made universities more efficient, it is questionable whether they have become more effective. As confirmed in this project, the lived experience of many academics, from nearly every university in Australia, much of any efficiency gains have been achieved through a deterioration in their working conditions.

Overall, there was a strong feeling that workload models, as they currently exist in universities, do not account for the full spectrum or complexity of academic work (Kenny \& Fluck, 2018, 2019; Miller, 2019). While some generally accounted for time associated with teaching (but not always adequately), many academics complained that little attention was given to capturing the time spent on research and service-related components of their work. This has clear implications for supporting individuals or judging their performance on a holistic basis.

Our findings confirm that capturing academic work is difficult. While our raw quantitative data showed large variations between individual estimates, we were able to use statistical analysis to derive realistic estimates for many activities. Our analysis of the qualitative data has expanded on a range of issues faced by academics around the country. The self-reported nature of the data, and that the sample was not fully representative of the academic population at the time, means these findings should be interpreted with some caution. However, the sample was large and included data from all but one of the 41 universities in Australia. These findings provide some insights into how the implementation of sectoral changes in universities can lead to perverse outcomes including the following: work overload and stress. They also illustrate how these contribute to a lack of trust by academics in the way corporate universities are managed.

However, while these findings show a negative impact on the working lives of many academics, which leaves them feeling exploited and/or taken for granted by their universities, they also suggest a way forward. First, by reiterating the central role academics play, through their high-quality teaching and research capabilities, in making universities effective; and second, by suggesting ways to improve the working relationship, between university management and their academic staff. Although this presents a challenge for both academics and their managers, it may improve the effectiveness of modern universities.

While calls for more shared governance may be a desirable longer-term goal, a more intermediate step would be to ensure workload and performance policies are strategically designed and resourced to capture the complexities of academic work, as suggested by Barrett and Barrett (2008). More specifically, this research suggests it is imperative that academics are fully involved in the development and operation of workload, performance and related policies which impact directly on their work. This has been shown to re-empower academics and rebuild trust (Kenny 2018; Kenny et al., 2012). Also, consistent with Barrett and Barrett (2008), these policies need to be adopted across an institution to ensure coherence of application and 
interpretation, by linking academic workload allocation and performance with other key policies, such as budgeting.

This leads us to propose some underlying principles which add to the literature by providing clearer guidance on the development and implementation of academic workload and performance policies in universities. The principles approach, first proposed by Aristotle (n.d.), argues complex problems need to be considered based on what is known. The power of this method is that it outlines key factors involved, so by implication, if any are not addressed, the effectiveness of the proposed solution will be reduced. Therefore, based on our review of the extant literature, our previous work and this further analysis, we propose that the following nine principles should underpin institutional policies and processes to determine the workload and performance of academics within universities.

\section{Principles to underpin academic work}

The policies related to academic work in a university need to be trustworthy. At the institution level, this will be achieved when:

1. They are developed, documented and implemented in full consultation with academic staff.

2. They are based on an acceptance of the intrinsically motivated and self-managed approach that academics are expected to take to their work.

3. They are adequately resourced, adopted across the institution and directly linked to other institutional processes such as budget and performance management.

4. The associated processes and tools are clearly visible and readily available to academic staff and their performance managers, to facilitate genuine negotiation about career goals, workload and performance expectations.

5. All staff and managers receive training in the application of the policies as required.

The outcomes for individual academics will be trustworthy when these policies:

6. Are applied in a fully transparent manner, in terms of process and outcome.

7. Provide a holistic estimate of an individual's workload, based on realistic time allocations for all key tasks they are expected to undertake in their teaching, research and administrative/service.

8. Are sufficiently flexible to cater for justifiable variations associated with differences in discipline, career stage and workload category.

9. Enable individual academics to negotiate reasonable workload and performance expectations that mirror their agreed work commitments.

These findings show how sector-wide policies can impact on the work of individual academics. Further, given that these data were provided by academics from all but one of the 41 universities in Australia, that these issues are widespread across the sector.

Moving forward into the second phase of the research, our goal is to develop a holistic academic workload estimation tool, incorporating the indicative time allocations derived from our research findings. This will be used in interviews with academics from around the country to validate the figures against their actual workloads and test their thoughts on the principles. This will lead to the refinement of the estimation tool and associated processes. The intention is to develop a transparent, holistic and credible means to enable any academic, irrespective of their institution, career stage or discipline, to realistically capture what they do. From this basis, they should be able to genuinely negotiate reasonable performance expectations with their managers, which acknowledge their individual circumstances and career aspirations.

With the severe financial pressures on universities due to the loss of overseas students because of the COVID-19 pandemic restrictions, the subsequent shift to online teaching and staff reductions (Universities Australia, 2021), the need for clarity on managing academic work and performance has become even more urgent. As many of these problems that Australian academics face mirror those of colleagues in other countries, these principles may have relevance for higher education sectors elsewhere. 


\section{References}

Aristotle (n.d.). Metaphysics 1013a, 14-15.

Australian Government. (2017). Data on Higher Education Sector. Department of Education. https://docs. education.gov.au/node/46156.

Barrett, L. C., \& Barrett, P. S. (2008). The management of academic workloads: full report on findings. University of Salford. http://usir.salford.ac.uk/691/.

Barry, D. (2019). Time to Re-think Australia's Higher Education Governance. Higher Education Consulting Group. https:/campusmorningmail.com.au/news/time-to-rethink-australias-higher-education-governance/

Bebbington, W. (2021). Leadership strategies for a higher education sector in flux. Studies in Higher Education, 46(1), 158-165. https://doi.org/10.1080/03075079.2020.1859686.

Bolden, R., Gosling, J., O’Brien, A., Peters, K., Ryan, M., \& Haslam, A. (2012). Academic leadership: changing conceptions, identities and experiences in UK higher education. Leadership Foundation for Higher Education.

Boyd, L. (2014). Exploring the utility of workload models in academe: a pilot study. Journal of Higher Education Policy and Management, 36(3), 315-326. https://doi.org/10.1080/01587919.2014.899050.

Burgess, T. F., Lewis, H. A., \& Mobbs, T. (2003). Academic workload planning revisited. Higher Education, 46(2), $215-233$.

Cannizzo, F., \& Osbaldiston, N. (2016). Academic work/life balance: a brief quantitative analysis of the Australian experience. Journal of Sociology, 52(4), 890-906. https://doi.org/10.1177/1440783315600803.

Coates, H., Goedegebuure, L. (2012). Recasting the academic workforce: why the attractiveness of the academic profession needs to be increased and eight possible strategies for how to go about this from an Australian perspective. Higher Education 64, 875-889. https://doi.org/10.1007/s10734-012-9534-3

Fleissner, P. (2006). Commodification, information, value and profit. Poiesis \& Praxis: International Journal of Technology Assessment and Ethics of Science, 4(1), 39-53.

Fredman, N., \& Doughney, J. (2012). Academic dissatisfaction, managerial change and neo-liberalism. Higher Education, 64, 41-58. https://doi.org/10.1007/s10734-011-9479-y.

Franco-Santos, M., Rivera, P., \& Bourne, M. (2014). Performance management in UK higher education institutions: the need for a hybrid approach. Report for Research and Development Series: Leadership Foundation for Higher Education Cranfield. School of management

Furlong, J. (2013). Globalisation, neo-liberalism and the reform of teacher education in England. Educ Forum, 77(1), 28-50. https://doi.org/10.1080/00131725.2013.739017.

Gill, R. (2014). Academics, cultural workers and critical labour studies. Journal of Cultural Economy, 7(1), 1230. https://doi.org/10.1080/17530350.2013.861763.

Glaser, B. G., \& Strauss, A. L. (1967). The discovery of grounded theory: strategies for qualitative research. Aldine.

Guthrie, J., Linnenluecke, M.K., Martin-Sardesai, A., Shen, Y. \& Smith T. (in review). On the resilience of Australian public universities: why our institutions may fail unless vice chancellors rethink broken business models. Macquarie University Business School working paper. https://www.dropbox.com/sh/ f3idf8xogq5r8rj/AAA35NWKaxYTmR2DF3V0FcFIa?dl=0

Harman, K., \& Treadgold, E. (2007). Changing patterns of governance for Australian universities. Higher Education Research \& Development, 26(1), 13-29.

Hénard, F., \& Mitterle, A. (2010), Governance and quality guidelines in higher education: a review of governance arrangements and quality assurance guidelines. OECD: Directorate for Education Programme on Institutional Management in Higher Education (IMHE). https://www.oecd.org/education/ imhe/46064461.pdf

Henkel, M. (2005). Academic identity and autonomy in a changing policy environment Higher Education, 49, 155-176.

Houston, D., Meyer, L. H., \& Paewai, S. (2006). Academic staff workloads and job satisfaction: expectations and values in academe. Journal of Higher Education Policy and Management, 28(1), 17-30. https://doi.org/10. $1080 / 13600800500283734$

Kauppinen, I. (2014). Different meanings of 'knowledge as commodity' in the context of higher education. Critical Sociology, 40(3), 393-409. https://doi.org/10.1177/0896920512471218.

Kenny J.D.J., (2008). Efficiency and effectiveness in higher education: Who is accountable for what? Australian Universities Review, 50(1) pp. 11-19. https://www.aur.org.au/archive/2000s

Kenny, J. (2017). Academic work and performativity. Higher Education, 74(5), 897-913. https://doi.org/10. 1007/s10734-016-0084-y.

Kenny, J. (2018). Re-empowering academics in a corporate culture: an exploration of workload and performativity in a university. Higher Education, 75(2), 365-380. https://doi.org/10.1007/s10734-017-0143-z

Kenny, J. \& Fluck, A.E. (2014). The effectiveness of academic workload models in an institution: a staff perspective, Journal of Higher Education Policy and Management, 36(6), 585-602. https://doi.org/10.1080/ 1360080X.2014.957889 
Kenny, J., \& Fluck, A. E. (2017). Towards a methodology to determine standard time allocations for academic work. Journal of Higher Education Policy and Management, 39(5), 503-523. https://doi.org/10.1080/ 1360080X.2017.1354773.

Kenny, J., \& Fluck, A. E. (2018). Research workloads in Australian Universities. Australian Universities' Review, 60(2), 25-37 https://www.aur.org.au/archive/2010s.

Kenny, J. \& Fluck, A.E. (2019). Academic administration \& service workloads in Australian Universities. Australian Universities Review, 61(2), 21-30. https://www.aur.org.au/archive/2010s

Kenny, J., Fluck, A. E., \& Jetson, T. (2012). Placing a value on academic work'. Australian Universities' Review, 54(2), 50-60.

Kwok, J.T. (2013). Impact of ERA research assessment on university behaviour and their staff. NTEU National Policy and Research Unit. Melbourne: National Tertiary Education Union. http://www.nteu.org.au/library/ view/id/3800

Langford, P. H. (2010). Benchmarking work practices and outcomes in Australian universities using an employee survey. Journal of Higher Education Policy and Management, 32(1), 41-53.

Marginson, S., \& Considine, M. (2000). The enterprise university: power, governance and reinvention in Australia. Cambridge University Press.

Miller, J. (2019). Where does the time go? An academic workload case study at an Australian university. Journal of Higher Education policy and management, 41(6), 633-645. https://doi.org/10.1080/1360080X.2019.1635328.

Mitchell, M. (2015). The university model is a victim of its own success. Australian Universities' Review, 57(2), 87-90 http://www.nteu.org.au/article/The-university-model-is-a-victim-of-its-own-success-\%28AUR-5702\%29-17935.

Morris, L. (2011). From collegial engagement to performance management: The changing academic landscape in Australia. In Thesis submitted in fulfilment of the requirements of a doctor of philosophy (PhD). Victoria University, School of Management and Information Systems.

Norton, A., Cherastidtham, I., and Mackey, W. (2018). Mapping Australian higher education 2018. Grattan Institute.

National Tertiary Education Union [NTEU] (2020). Workloads - Academic Staff. http://www.nteu.org.au/policy/ workforce issues/workloads

Office of Industrial Relations (2018). Education and training industry: Statistical update 2009-14. Queensland Government. https://www.worksafe.qld.gov.au/_data/assets/pdf_file/0018/25191/education-trainingindustry-statistical-update-2009-14.pdf

Papadopoulos, A. (2017). The mismeasure of academic labour. Higher Education Research \& Development, 36(3), 511-525. https://doi.org/10.1080/07294360.2017.1289156

Pink, D. (2010). Drive: the surprising truth about what motivates us. Canongate books.

Ryan, S., Burgess, J., Connell, J. \& Groen, E. (2013): Casual academic staff in an Australian university: marginalised and excluded, Tertiary Education and Management, 19(2), 161-175. https://doi.org/10. $1080 / 13583883.2013 .783617$

Roberts, P. (2013). Academic dystopia: knowledge, performativity, and tertiary education. Review of Education, Pedagogy, and Cultural Studies, 35(1), 27-43. https://doi.org/10.1080/10714413.2013.753757.

Safe Work Australia. (2021). Workers' compensation statistics 2018-19. Author.

Söderlind, J., \& Geschwind, L. (2019). Making sense of academic work: the influence of performance measurement in Swedish universities. Policy Reviews in Higher Education, 3(1), 75-93. https://doi.org/ 10.1080/23322969.2018.1564354.

Strauss, J., \& Corbin, A. (1990). Grounded theory research: procedures, canons and evaluative criteria. Qualitative Sociology, 13(1), 3-21.

Tight, M. (2010). Are academic workloads increasing? The post-war survey evidence in the UK. Higher Education Quarterly, 64(2), 200-215. https://doi.org/10.1111/j.1468-2273.2009.00433.x.

Universities Australia (2021). Media release. https://www.universitiesaustralia.edu.au/media-item/17000-unijobs-lost-to-covid-19/

Vardi, I. (2009). The impacts of different types of workload allocation models on academic satisfaction and working life. Higher Education, 57(4), 499-508. https://doi.org/10.1007/s10734-008-9159-8

Vesty, G., Sridharan, V., Northcott, D., \& Dellaportas, S. (2018). Burnout among university accounting educators in Australia and New Zealand: Determinants and implications. Accounting \& Finance, 58(1), 255-277. https://doi.org/10.1111/acfi.12203.

Yielder, J., \& Codling, A. (2004). Management and leadership in the contemporary university. Journal of Higher Education Policy and Management, 26(3), 315-328.

Publisher's note Springer Nature remains neutral with regard to jurisdictional claims in published maps and institutional affiliations. 